\title{
Extrapolation of Animal Research Data to Humans: An Analysis of the Evidence
}

\author{
Rebecca Ram \\ Clinical Data Management and Scientific Research Consultant \\ rebeccanram@aol.com
}

The ethical arguments against animal experimentation remain ever-strong. In addition, the scientific case against the use of animals in research grows more compelling, with exponential progress in the development of alternative methods and new research technologies. The Dutch authorities recently announced an ambitious, but welcome, proposal to phase out "the use of laboratory animals in regulatory safety testing of chemicals, food ingredients, pesticides and (veterinary) medicines" by 2025, as well as "the use of laboratory animals for the release of biological products, such as vaccines" (Netherlands National Committee for the protection of animals used for scientific purposes, NCad, 2016, p. 3). National government departments (e.g., the United Kingdom, UK, Home Office) have stated that alternatives to animals are now considered necessary for scientific as much as ethical reasons, also conceding that pressure exists within the research community to use animals in order to get published. Furthermore, only $20 \%$ of animal tests across the European Union (EU) each year are conducted to meet regulatory requirements, with the vast majority carried out as basic research (including basic medical research) or breeding of genetically modified (GM) animals at academic institutions (European Commission, 2013b).

Despite the strength of both scientific and moral arguments, animal research continues to increase worldwide, especially given the rising trend in use of GM animals. A Catch 22 situation also exists, with regulators largely refusing to break with tradition and continuing to accept only animal data, even when robust human-based data exists. Additionally, when new animal-free, human-relevant methods are developed, regulators often insist that research still be performed on animals; this is considered to be one of the major barriers to achieving change and, in turn, results in an industry reluctant to invest 
in non-animal research, if its results are unlikely to be accepted (Schiffelers et al., 2012).

Whilst public engagement, via campaigns to highlight animal suffering, remains vital, a renewed focus on scientific, political, and financial interests is needed. This focus is needed to emphasize the fundamental message that animal research simply does not deliver what is needed, in order to influence those who regulate, finance, or approve animal experiments and have a meaningful impact on their ongoing reduction but primarily, their replacement. Scientific evidence is needed, on an ongoing basis, of the inadequacy of animal experiments in predicting human outcomes, combined with a focus on the modern, non-animal techniques that have the potential to replace them, to drive an ongoing recognition of the need for genuine, significant investment in human-relevant research. Additionally, not all animal tests need replacing, many can simply end; so providing appropriate evidence of these types of tests is also essential.

In striving to achieve a paradigm shift to end animal experimentation, for scientific as much as ethical reasons, an evidence-based approach is required. There remains a vital need for a combination of drivers in innovative, animalfree scientific research, training, and education, as well as continued lobbying and campaigning to key stakeholders (i.e., scientists, regulators, and political audiences).

Animal experimentation falls into two broad categories: basic research (including basic medical research) and a relatively smaller category, toxicity (or safety) testing of new substances, which includes chemicals for use in personal care, household products, industrial substances, foodstuffs, or pharmaceuticals (the latter are also tested for efficacy). There is overlap, to some extent, in these categories, with some animal procedures categorized as "fundamental toxicology", for example. A two-fold strategy is suggested to end the use of animals in all experimental research. The first should focus on how a large number of procedures performed, both in basic research and product-safety testing, can simply end today; in other words, they do not need non-animal replacements. The second should focus on procedures that are considered to require replacement. This could be through intelligent and strategic combinations of existing non-animal tests (integrated testing strategies) and/or further development of new human-relevant models. Examples of these and their success in replacing animals to date are discussed later in this chapter.

A popular argument in support of continuing animal research is that they have been used for decades in the research and development of new medicines. The fact that millions of animals have been used over years, often in the same repeated experiments, is not in dispute. However, their continued 
use does not prove necessity. It is also relevant to note that from early on in a scientific career, one is discouraged from saying that experiments "didn't work" but instead, to conclude how further research or new approaches must be tried next, in light of unsuccessful or unexpected results. The use of animals has been grandfathered through, due to convention, anecdotal evidence or belief, rather than robust scientific validity. "We must use a living system" ... but it is the wrong living system and no matter how many animals are used, they will never provide an appropriate model for humans. This needs to change, particularly when considering the growing industry of breeding and supplying millions of GM animals worldwide each year, in repeated attempts to mimic the human condition.

The vast majority of animals are used either for basic research or breeding of GM strains. This is clear when reviewing recent official statistics for the three highest animal-using countries in the EU; the UK, Germany, and France. For example, more than 3.9 million procedures on animals (mice, rats, rabbits, guinea pigs, dogs, horses, cats, non-human primates, pigs, sheep, cattle, birds, xenopus, and fish, among other species) were carried out in the UK in 2016. Of these, 729,390 were genetically modified, including more than 149,000 animals deliberately bred to suffer a harmful phenotype (a deliberately induced condition, such as cancer, failed immune system, or organ failure to try to simulate disease in humans). There were also increases in the number of experiments across several species, and a significant number of experiments for ingredients in household products (1700 procedures), to meet industrial chemicals legislation requirements, despite a policy on testing for such purposes (Home Office, 2017). In fact, of the total 3.9 million procedures conducted in the UK in 2016, only $13 \%$ were carried out for regulatory purposes. Germany bred 1.2 million GM animals in 2015 (with similar numbers of harmful phenotype animals to the UK), representing $42 \%$ of the 2.8 million animals used annually (Federal Ministry of Food and Agriculture, 2016). Figures reported for France in 2014 show that 1.8 million animals were used, however the proportion of GM animals was not reported (Ministry of Higher Education \& Research, 2016).

Several thousand diseases affect humans. Of these, only 500 currently have FDA-approved treatments available (National Center for Advancing Translational Sciences, 2017). In every discipline of disease research, animals are used on an ongoing basis, yet it is continually reported that mechanisms of human conditions investigated in such animals are still not understood. This is because basic research in animals is a demand-driven and self-perpetuating system, with much research being proposed and licensed on the basis of being repetitively performed on animals (often termed as "well established" or "well documented" models). Such research is neither legally required, nor does it 
have to be relevant or applicable to human disease to be licensed. Another key barrier to replacing animals, even when scientifically valid alternatives are available, is awareness and acceptance of their use, both by researchers and regulators (Ramirez et al., 2015).

The first part of this chapter provides an analysis of extrapolation of animal studies to humans, by sampling systematic reviews carried out to assess evidence of clinical translation and incorporating a review of literature on animal toxicity studies for some well-known, established case study drugs (e.g., paracetamol, aspirin, penicillin) and animal versus human findings. The second part addresses drivers for change and the development of animal-free (or rather, human-relevant) research methods, as well as some examples of procedures that do not need replacing as they can simply stop, when considering that they can logically be avoided or rejected on the basis of a correctly performed (and legally required) harm-benefit assessment. The chapter aims to provide an overview of the above topics and suggestions for the way forward as part of a new paradigm for a global, animal-research free future.

\section{Part 1: Analysis of Abstracts from Systematic Reviews of Animal Studies}

To carry out an analysis of systematic reviews on animal experiments, a review of a sample of available literature was performed. The intention of this analysis was to provide a generally qualitative review of the literature. To do so, two separate sources were used. First, a search in PubMed (National Centre for Biotechnology Information, 2016) was made using the keyword search of "systematic review animal studies." This resulted in a total of 163,585 publications. PubMed allows search by Article Type and selecting this as "systematic review" further filtered results to 8,291 listings, also sorted by relevance. Second, the Google Scholar database, using the same search terms, "systematic review animal studies," for consistency, yielded 2,530,00o results (Google Scholar, 2016). Dates of publications ranged from 1999-present. Generally, PubMed provided more recent listings compared to Google Scholar, which resulted in older publications; but this was useful to provide a greater scope for review over the past two decades as well as avoid duplication.

To account for time constraints, while still providing a reasonable sample size, the first $5^{0}$ abstract listings within each source were reviewed, giving a sample total of 100 (see Table 15.1). If a publication appeared within both sources, this was also accounted for, although duplicates were relatively few. Where publications were found to be not relevant, further listings were reviewed to compensate for this and to maintain a total of 100. 
Andersen, K., Pedersen, T.K., Hauge, E.M., Schou, S. and Nørholt, PubMed S.E. (2014). Effect of Mandibular Distraction Osteogenesis on the Temporomandibular Joint: A Systematic Review of Animal Experimental Studies. Oral Surgery, Oral Medicine, Oral Pathology, Oral Radiology, 117(4), pp. 407-415 ardant, M., Lagarde, M. and Bernoud-Hubac, N. (2016). The Pleiotropic Effects of Omega-3 Docosahexaenoic Acid on the Hallmarks of Alzheimer's Disease. Journal of Nutritional Biochemistry, 38, pp. 1-11. The Relationship Between Study Sponsorship, Risks of Bias, and Research Outcomes in atrazine Exposure Studies Conducted in Non-human Animals: Systematic Review and Meta-analysis. Environment International, 92-93, pp. 597-6o4. Motschall, E., Gloy, V., Lamontagne, F., Schwarzer, G. and Bassler, D. (2013). Publication Bias in Animal Research: A Systematic Review Protocol. Systematic Reviews, 27(2), p. 23. Tallón-Walton, V. and Manzanares-Céspedes, M.C. (2014). Tooth Movement in Orthodontic Treatment with Low-level Laser Therapy: A Systematic Review of Human and Animal Studies. Photomedicine and Laser Surgery, 32(5), pp. 302-309. (2016). The Cardiopulmonary Effects and Quality of Anesthesia After Induction with Alfaxalone in 2-hydroxypropyl- $\beta$ cyclodextrin in Dogs and Cats: A Systematic Review. Journal of Veterinary Pharmacology and Therapeutics, 39(6), pp. 525-538. Disma, N., Mondardini, M., Terrando, N., Absalom, A. and Bilotta, PubMed F. (2016). A Systematic Review Of Methodology Applied During Preclinical Anesthetic Neurotoxicity Studies: Important Issues and Lessons Relevant to the Design of Future Clinical Research. Paediatric Anaesthesia, 26(1), pp. 6-36.

8 Emmens, R., Wouters, D., Zeerleder, S., van Ham, S., Niessen, H. and Krijnen, P. (2016). On the Value of Therapeutic Interventions Targeting the Complement System in Acute Myocardial Infarction. Translational Research, pp. S1931-5244. 

Tu, Y.K. (2010). Comparison of the Effects of Treatment of Periimplant Infection in Animal and Human Studies: Systematic Review and Meta-analysis. Clinical Oral Implants Research, 21(2), pp. 137-147. of Animal Studies on Regenerative Procedures for Periodontal and Peri-implant Bone Defects. A Systematic Review. Journal of Clinical Periodontology. 38(12), pp. 1154-116o. Fliefel, R., Kühnisch, J., Ehrenfeld, M. and Otto, S. (2016). Gene Therapy for Bone Defects in Oral and Maxillofacial Surgery: A Systematic Review and Meta-analysis of Animal Studies. Stem Cells Development, Epub ahead of print.

12 Gates, S., Smith, J.L., Ong, G.J., Brace, S.J. and Perkins, G.D. (2012). PubMed Effectiveness of the LUCAs Device for Mechanical Chest Compression After Cardiac Arrest: Systematic Review of Experimental, Observational and Animal Studies. Heart, 98(12), pp. 908-913.

13 Gulin, J.E., Rocco, D.M. and García-Bournissen, F. (2015). Quality PubMed of Reporting and Adherence to ARRIVE Guidelines in Animal Studies for Chagas Disease Preclinical Drug Research: A Systematic Review. Public Library of Science Neglected Tropical Diseases, 20:9(11). Andrews, P.J. (2016). Study Protocol: A Systematic Review and Meta-analysis of Hypothermia in Experimental Traumatic Brain Injury: Why Have Promising Animal Studies Not Been Replicated in Pragmatic Clinical Trials?. Evidence-based Preclinical Medicine, 3(2), p. eooo2o. Gama E.F. (2015). Effects of Exercise on Neuromuscular Junction Components Across Age: Systematic Review of Animal Experimental Studies. BioMed Central Research Notes, 24(8), p. 713. Krauth, D., Woodruff, T. and Bero, L. (2013). Instruments for Assessing Risk of Bias and Other Methodological Criteria of Published Animal Studies: A Systematic Review. Environmental Health Perspectives, 121(9), pp. 985-992. 
17 Lee, S.H., van den Noort, M., Bosch, P. andLim, S. (2016). Sex

PubMed Differences in Acupuncture Effectiveness in Animal Models of Parkinson's Disease: A Systematic Review. BioMed Central Complementary and Alternative Medicine, 3, 16(1), p. 430. (2014). Mechanisms Underlying the Effect of Acupuncture on Cognitive Improvement: A Systematic Review of Animal Studies. Journal of Neuroimmune Pharmacology, 9(4), pp. 492-507.

19 Li, J., Hernanda, P.Y., Bramer, W.M., Peppelenbosch, M.P., van PubMed Luijk, J. and Pan, Q. (2015). Anti-tumor Effects of Metformin in Animal Models of Hepatocellular Carcinoma: A Systematic Review and Meta-analysis. PLoS One, 1;10(6), p. eo127967. Liao, Y., Zhang, X.L., Li, L., Shen, F.M. and Zhong, M.K. (2014). Stem Cell Therapy for Bone Repair: A Systematic Review and Meta-analysis of Preclinical Studies with Large Animal Models. British Journal of Clinical Pharmacology, 78(4), pp. 718-726. McClelland, J., Bozhilova, N., Campbell, I. and Schmidt, U. (2013). PubMed A Systematic Review of the Effects of Neuromodulation on Eating and Body Weight: Evidence from Human and Animal Studies.

European Eating Disorders Review, 21(6), pp. 436-455. McDonald J., Eng, S., Dina, O., Schooling, C. and Terry, M. (2016). PubMed Infection and Pubertal Timing: A Systematic Review. Journal of Developmental Origins of Health and Disease, 7(6), pp. 636-651 Mueller, K.F., Briel, M., Strech, D., Meerpohl, J.J., Lang, B., PubMed Motschall, E., Gloy, V., Lamontagne, F. and Bassler, D. (2014). Dissemination Bias in Systematic Reviews of Animal Research: A Systematic Review. PLoS One, 26, 9(12), p. e116o16. Muhlhausler, B.S., Gibson, R.A. and Makrides, M.(2011). The Ef- PubMed fect of Maternal Omega-3 Long-chain Polyunsaturated Fatty Acid (n-3 LCPUFA) Supplementation During Pregnancy and/or Lactation on Body Fat Mass in the Offspring: A Systematic Review of Animal Studies. Prostaglandins, Leukotrienes, and Essential Fatty Acids (PLEFA), 85(2), pp. 83-88. 
26 Naumann, D., Beaven, A., Dretzke, J., Hutchings, S. and Midwinter, PubMed M. (2016). Searching for the Optimal Fluid to Restore Microcirculatory Flow Dynamics after Haemorrhagic Shock: A Systematic Review of Preclinical Studies. Shock. 46(6), pp. 6o9-622.

27 Noorimotlagh, Z., Haghighi, N., Ahmadimoghadam, M. and PubMed Rahim, F. (2016). An Updated Systematic Review on the Possible Effect of Nonylphenol on Male Fertility. Environmental Science and Pollution Research International, 24(4), pp. 3298-3314.

28 Parker, T., Nguyen, A., Rabang, J., Patil, A. and Agrawal, D.(2016). PubMed The Danger Zone: Systematic Review of the Role of HMGB 1 Danger Signaling in Traumatic Brain Injury. Brain Injury, 7, pp. 1-7.

29 Pot, M.W., Gonzales, V.K., Buma, P., IntHout, J., van Kuppevelt, PubMed T.H., de Vries, R.B. and Daamen, W.F. (2016). Improved Cartilage Regeneration by Implantation of Acellular Biomaterials after Bone Marrow Stimulation: A Systematic Review and Meta-analysis of Animal Studies. PeerJ, 8, 4, p. e2243.

30 Qi, N., Li, W.J. and Tian, H. (2016). A Systematic Review of Animal PubMed and Clinical Studies on the Use of Scaffolds for Urethral Repair. Journal of Huazhong University of Science and Technology. Medical Sciences, 36(1), pp. 111-117.

31 Raavé R., de Vries, R.B., Massuger, L.F., van Kuppevelt, T.H. and PubMed Daamen, W.F. (2015). Drug Delivery Systems for Ovarian Cancer Treatment: A Systematic Review and Meta-analysis of Animal Studies. PeerJ, 10, 3, p. e1489. Frequency, Food Intake, and Weight: A Systematic Review of Human and Animal Experimental Studies. Frontiers in Nutrition, 2(38), pp. 1-19.

Reis, J., Monteiro, V., de Souza, R., do Carmo, M., da Costa, G., Ribera, P. and Monteiro, M. (2016). Action Mechanism and Cardiovascular Effect of Anthocyanins: A Systematic Review of Animal and Human Studies. Journal of Translational Medicine, 14(1), p. 315 . 
Ness, A.R., Penfold, C., Perry, R., Putz, P., Yeomans, M.R. and Mela, D.J. (2016). Does Low-energy Sweetener Consumption Affect Energy Intake and Body Weight? A Systematic Review, Including Meta-analyses, of the Evidence from Human and Animal Studies. International Journal of Obesity (London), 40(3), pp. 381-394. Sabit, B., Zeiler, F. and Berrington, N. (2016). The Impact of Mean PubMed Arterial Pressure on Functional Outcome Post-Acute Spinal Cord Injury: A Scoping Systematic Review of Animal Models. Journal of Neurotrauma. doi: 10.1089/neu.2016.4735. G., and Abdollahi, M. (2016). Recent Updates in Imperative Natural Compounds for Healthy Brain and Nerve Function: A Systematic Review of Implications for Multiple Sclerosis. Current Drug Targets. Epub ahead of print. Other Non-coding RNAs in Posttraumatic Stress Disorder: A Systematic Review of Clinical and Animal Studies. Journal of Psychiatric Research, 65, pp. 1-8.

38 Sendyk, D.I., Deboni, M.C., Pannuti, C.M., Naclério-Homem, M.G. PubMed and Wennerberg, A. (2016). The Influence of Statins on Osseointegration: A Systematic Review of Animal Model Studies. Journal of Oral Rehabilitation, 43(11), pp. 873-882. los, A. (2016). Cell Cotransplantation Strategies for Vascularized Craniofacial Bone Tissue Engineering: A Systematic Review and Meta-Analysis of Preclinical In Vivo Studies. Tissue Engineering Part B Reviews, Epub ahead of print. Z. (2015). The Impact of Ginsenosides on Cognitive Deficits in Experimental Animal Studies of Alzheimer's Disease: A Systematic Review. BioMed Central Complementary and Alternative Medicine, 24(15), p. 386. tent Sexual Dysfunction after Early Exposure to ssR Is: Systematic Review of Animal Studies. International Journal of Risk \& Safety in Medicine, 16,28(1), pp. 1-12. in Animal Bleomycin Pulmonary Fibrosis Models: A Systematic Review. Stem Cells Translational Medicine, 4(12), pp. 1500-1510. 
TABLE 15.1 Publications included in abstract review ( $\mathrm{n}=100)$ (cont.) of Interventional Animal Studies in Rheumatology: A Systematic Review Using the ARRIVE Guidelines. International Journal of Rheumatic Diseases, 18(5), pp. 488-494. (2016). Renal Perfusion and Function During Pneumoperitoneum: A Systematic Review and Meta-analysis of Animal Studies. PLoS One, 11(9), p. eo163419.

Wever, K.E., Hooijmans, C.R., Riksen, N.P., Sterenborg, T.B., Sena, E.S., Ritskes-Hoitinga, M. and Warlé M.C. (2015). Determinants of the Efficacy of Cardiac Ischemic Preconditioning: A Systematic Review and Meta-analysis of Animal Studies. PLoS One, 10(11), p. e0142021.

46 Yarlagadda, S., Coca, S., Garg, A., Doshi, M., Poggio, E., Marcus, PubMed R. and Parikh, C. (2008). Marked Variation in the Definition and Diagnosis of Delayed Graft Function: A Systematic Review. Nephrology Dial Transplantation, 23 (9), pp. 2995-3003. Yen, C.C., Tu, Y.K., Chen, T.H. and Lu, H. (2014). Comparison of PubMed Treatment Effects of Guided Tissue Regeneration on Infrabony Lesions Between Animal and Human Studies: A Systematic Review and Meta-analysis. Journal of Periodontal Research, 49(4), pp. 415-424.

48 Zeng, X., Zhang, Y., Kwong, J.S., Zhang, C., Li, S., Sun, F., Niu, Y. and PubMed Du L. (2015). The Methodological Quality Assessment Tools for Preclinical and Clinical Studies, Systematic Review and Metaanalysis, and Clinical Practice Guideline: A Systematic Review. Journal of Evidence-Based Medicine, 8(1), pp. 2-10. (2014). Efficacy of Combination Therapy of Triazole and Echinocandin in Treatment of Invasive Aspergillosis: A Systematic Review of Animal and Human Studies. Journal of Thoracic Disease, 6(2), pp. 99-108.

$5^{0} \quad$ Zwetsloot, P.P., Végh, A.M., Jansen of Lorkeers, S.J., van Hout, G.P., PubMed Currie, G.L., Sena, E.S., Gremmels, H., Buikema, J.W., Goumans, M.J., Macleod, M.R., Doevendans, P.A., Chamuleau, S.A. and Sluijter, J.P.(2016). Cardiac Stem Cell Treatment in Myocardial Infarction: A Systematic Review and Meta-analysis of Preclinical Studies. Circulation Research, 5, 118(8), pp. 1223-1232. 
Aghajafari, F., Murphy, K., Matthews, S., Ohlsson, A., Amankwah, Google K. and Hannah, M. (2002). Repeated Doses of Antenatal Corti- Scholar costeroids in Animals: A Systematic Review. American Journal of Obstetrics \& Gynecology, 186(4), pp. 843-849. pp. 570-587. tion in Traumatic Spinal Cord Injury: A Systematic Review and Meta-analysis of Animal Studies. Public Library of Science Biology, $11(12)$, p. e1001738. the ADQI Workgroup. (2004). Acute Renal Failure-Definition, Scholar Outcome Measures, Animal Models, Fluid Therapy and Information Technology Needs: The Second International Consensus Conference of the Acute Dialysis Quality Initiative (ADQI) Group. Critical Care, 8, R204. Bjordal, J., Johnson, M., Iversen, V., Aimbire, F. and Lopes-Martins, Google R. (2006). Low-level Laser Therapy in Acute Pain: A Systematic Scholar Review of Possible Mechanisms of Action and Clinical Effects in Randomized Placebo-controlled Trials. Photomedicine and Laser Surgery, 24(2), pp. 158-168. Antidote Beyond Local Anesthetic Toxicity, A Systematic Review. Scholar Academic Emergency Medicine, 16(9), pp. 815-824. vention in Min Mice and Choice of the Model System. Cancer Epidemiology, Biomarkers \& Prevention, 12(5), pp. 391-40o. Corpet, D. and Pierre, F. (2005). How Good Are Rodent Models of Google Carcinogenesis in Predicting Efficacy in Humans? A Systematic Scholar Review and Meta-analysis of Colon Chemoprevention in Rats, Mice and Men. European Journal of Cancer, 41(13), pp. 1911-1922. R. (2010). Nutrition-related Health Effects of Organic Foods: A Scholar Systematic Review. American Journal of Clinical Nutrition, 92(1), pp. $203^{-210 .}$ 

Multidrug-resistant Non-fermenting Gram-negative Bacilli: A Systematic Review of Microbiological, Animal and Clinical Studies. International Journal of Antimicrobial Agents, 34(2), pp. 111-120.

61 Fehlings, M. and Perrin, R. (2006). The Timing of Surgical InterGoogle vention in the Treatment of Spinal Cord Injury: A Systematic Scholar Review of Recent Clinical Evidence. Spine, 15;31(11), pp. S28-36. Giannobile, W. and Somerman, M. (2003). Growth and AmeloGoogle genin-like Factors in Periodontal Wound Healing, A Systematic Scholar Review. Annals of Periodontology, 8(1), pp. 193-204.

63 Gibson, C., Gray, L., Bath, P. and Murphy, S. (2008). Progesterone for the Treatment of Experimental Brain Injury; A Systematic Scholar Review. Brain, 131 (2), pp. 318-328.

64 Gibson, C. and Murphy, S. (2010). Benefits of Histone Deacetylase Google Inhibitors for Acute Brain Injury: A Systematic Review of Animal Scholar Studies. Journal of Neurochemistry, 115(4), pp. 8o6-813.

65 Hasani-Ranjbar, S., Nayebi, N., Larijani, B. and Abdollahi, M. Google (2009). A Systematic Review of the Efficacy and Safety of Herbal Scholar Medicines Used in the Treatment of Obesity. World Journal of Gastroenterology, 15(25), pp. 3073-3085.

66 Henderson, V., Kimmelman, J., Fergusson, D., Grimshaw, J. and Google Hackam, D. (2013). Threats to Validity in the Design and Conduct Scholar of Preclinical Efficacy Studies: A Systematic Review of Guidelines for In Vivo Animal Experiments. Public Library of Science Medicine, $10(7)$, p. e1001489.

67 Hooijmans, C., Leenaars, M. and Ritskes-Hoiting, M. (2010). Google A Gold Standard Publication Checklist to Improve the Quality Scholar of Animal Studies, to Fully Integrate the Three Rs, and to Make Systematic Reviews More Feasible. Alternatives to Laboratory Animals, 38(2), pp. 167-182.

68 Horn, J., de Haan, R., Vermeulen, M., Luiten, P. and Limburg, M. Google (2001). Nimodipine in Animal Model Experiments of Focal Cere- Scholar bral Ischemia: A Systematic Review. Stroke, 32(10),

pp. 2433-2438. 
69 Houben, M., van de Beek, D., Hensen, E., de Craen, A., Rauws, E. Google and Tytgat, G. (1999). A Systematic Review of Helicobacter Pylori Scholar Eradication Therapy - The Impact of Antimicrobial Resistance on Eradication Rates. Alimentary Pharmacology \& Therapeutics, 13(8), pp. 1047-1055. Poisoning: A Systematic Review of Human and Animal Studies. Clinical toxicology (Philadelphia, PA ), 48(1), pp. 1-27. Javed, F. and Romanos, G. (2009). Impact of Diabetes Mellitus and Glycemic Control on the Osseointegration of Dental Im- Scholar plants: A Systematic Literature Review. Journal of Periodontology, 80 (11), pp. 1719-1730. Junker, R., Dimakis, A., Thoneick M. and Jansen, J. (2009). Effects of Implant Surface Coatings and Composition on Bone Integration: A Systematic Review. Clinical Oral Implants Research, 20 (s4), pp. 185-206. (2010). Improving Bioscience Research Reporting: The ARRIVE Scholar Guidelines for Reporting Animal Research. Journal of Pharmacology and Pharmacotherapeutics, 1(2), pp. 94-99. Fehlings, M. and Tetzlaff, W. (2011). A Systematic Review of Scholar Non-invasive Pharmacologic Neuroprotective Treatments for Acute Spinal Cord Injury. Journal of Neurotrauma, 28(8), pp. $1545^{-1} 5^{88 .}$ D., Guyatt, G., Lesur, O. and Meade, M. (2010). Systematic Review Scholar of Reviews Including Animal Studies Addressing Therapeutic Interventions for Sepsis. Critical Care Medicine, 38(12),

pp. 2401-2408.

76 Langenberg, C., Bagshaw, S., May, C. and Bellomo, R. (2008). Google The Histopathology of Septic Acute Kidney Injury: A Systematic Scholar Review. Critical Care, $12(2), \mathrm{R}_{3} 8$.

77 Lerchbaum, E. and Obermayer-Pietsch, B. (2012). Vitamin D and Google Fertility: A Systematic Review. European Journal of Endocrinology, Scholar 166, pp. $765^{-778 .}$

78 Lucas, C., Criens-Poublon, L., Cockrell, C. and de Haan, R. (2002). Google Wound Healing in Cell Studies and Animal Model Experiments Scholar by Low Level Laser Therapy; Were Clinical Studies Justified? A Systematic Review. Lasers in Medical Science, 17(2), pp. 110-134. 

tion Strategies: A Systematic Review of Animal Trials. Journal of Scholar Trauma-Injury Infection \& Critical Care, 55(3), pp. 571-589.

$80 \quad$ Navas-Acien, A., Silbergeld, E., Streeter, R., Clark, J., Burke, T. and Eliseo Guallar, E. (2006). Arsenic Exposure and Type 2 diabetes: Scholar A Systematic Review of the Experimental and Epidemiologic Evidence. Environmental Health Perspectives, 114(5), pp. 641-648.

81 Perel, P., Roberts, I., Sena, E., Wheble, P., Briscoe, C., Sandercock, P., Macleod, M., Mignini, L., Jayaram, P. and Khan, K. (2007). Comparison of Treatment Effects Between Animal Experiments and Clinical Trials: Systematic Review. British Medical Journal, 334(7586), p. 197.

82 Perlroth, J., Kuo, M., Tan, J., Bayer, A. and Miller, L. (2008). Adjunc- Google tive Use of Rifampin for the Treatment of Staphylococcus Aureus Scholar Infections: A Systematic Review of the Literature. Archives of Internal Medicine, 168(8), pp. 805-819.

83 Pilchera, J., Weatherall, M., Shirtcliffe, P., Bellomod, R., Young, P. Google and Beasley, R.(2012). The Effect of Hyperoxia Following Cardiac Scholar Arrest-A Systematic Review and Meta-analysis of Animal Trials. Resuscitation, 83(4), pp. 417-422.

84 Rahimi, R., Mozaffari, S. and Abdollahi, M. (2009). On the Use Google of Herbal Medicines in Management of Inflammatory Bowel Diseases: A Systematic Review of Animal and Human Studies. Digestive Diseases and Sciences, 54(3), pp. 471-48o.

85 Ramberg, J., Nelson, E. and Sinnott, R. (2010). Immunomodulato- Google ry Dietary Polysaccharides: A Systematic Review of the Literature. Scholar Nutrition Journal, 9, p. 54.

86 Ren, Y., Maltha, J. and Kuijpers-Jagtman, A. (2003). Optimum Google Force Magnitude for Orthodontic Tooth Movement: A Systematic Scholar Literature Review. The Angle Orthodontist, 73(1), pp. 86-92.

87 Rice, A., Cimino-Brown, D., Eisenach, J., Kontinen, V., LacroixFralish, M., Machin, I. (on behalf of the Preclinical Pain ConGoogle sortium), Mogil, J. and Stöhr, T. (2008). Animal Models and the Prediction of Efficacy in Clinical Trials of Analgesic Drugs: A Critical Appraisal and Call for Uniform Reporting Standards. Pain, 139 (2), pp. 243-247. 

tion of Periodontal Tissues: Combinations of Barrier Membranes Scholar and Grafting Materials - Biological Foundation and Preclinical Evidence: A Systematic Review. Journal of Clinical Periodontology, 35(8), pp. 106-116.

$89 \quad$ Sena, E., van der Worp, H., Bath, P., Howells, D. and Macleod, M. (2010). Publication Bias in Reports of Animal Stroke Studies

Google Leads to Major Overstatement of Efficacy. Public Library of Science Biology, 30,8(3), p. e1000344. Shalabi, M., Gortemaker, A., Van't Hof, M., Jansen, J. and Creugers, Google N. (2006). Implant Surface Roughness and Bone Healing: A Systematic Review. Journal of Dental Research, 85(6), pp. 496-500. Subramaniam, K., Subramaniam, B. and Steinbrook, R. (2004). Scholar Ketamine as Adjuvant Analgesic to Opioids: A Quantitative and Google Qualitative Systematic Review. Anaesthesia \& Analgesia, 99(2), pp. 482-495. Plemel, J., Plunet, W., Tsai, E., Baptiste, D., Smithson, L., Kawaja, Scholar M., Fehlings, M. and Kwon, B. (2011). A Systematic Review of Cellular Transplantation Therapies for Spinal Cord Injury.Journal of Neurotrauma, 28(8), pp. 1611-1682. Ulbrich, B. and Stahlmann, R. (2004). Developmental Toxicity of Google Polychlorinated Biphenyls (PCBs): a Systematic Review of Experi- Scholar mental Data. Archives of Toxicology, 78(5), pp. 252-268. van der Spoel, T., Jansen of Lorkeers, S., Agostoni, P., van Belle, Google E., Gyöngyösi, M., Sluijter, J., Cramer, M., Doevendans, P. and Scholar Chamuleau, S. (2011). Human Relevance of Preclinical Studies in Stem Cell Therapy: Systematic Review and Meta-analysis of Large Animal Models of Ischaemic Heart Disease. Cardiovascular Research, 91(4), pp. 649-658. O'Collins, V. and Macleod M.R. (2010). Can Animal Models of Scholar Disease Reliably Inform Human Studies? Public Library of Science Medicine, 7(3), p. e1000245.

96 van der Worp, H., Sena, E., Donnan, G., Howells, D. and Macleod, Google M. Hypothermia in Animal Models of Acute Ischaemic Stroke: A Scholar Systematic Review and Meta-analysis. (2007). Brain, 130(12), pp. 3063-3074. 

of Resveratrol. PLoS One, 6(6), p. e19881.

98 Wennerberg, A. and Albrektsson, T. (2009). Effects of Titanium tegration and Clinical Success of Zirconia Dental Implants: A Systematic Review. Source. International Journal of Prosthodontics, 21 (1), pp. 27-36.

M. (2012). Ischemic Preconditioning in the Animal Kidney: A

Systematic Review and Meta-analysis. PLoS One, 7(2), p. e32296.

Relevant abstracts were assessed overall, depending on the following information:

- Clear concordance between human and animal studies.

- Limited concordance between human and animal studies.

- Lack of concordance between human and animal studies, due to one of the following factors: Unclear reporting, bias, inconsistency, species differences, heterogeneity, and lack of clinical translation.

It should be noted that the term concordance in this context refers to a qualitative, rather than quantitative analysis of the literature within the available timeframe. It is also important to note that the systematic reviews analyzed and the studies included within these publications (based on eligibility criteria assigned by the authors) are just a fraction of thousands of papers reviewed but rejected, some spanning four or five decades and using hundreds of thousands of animals.

Of the 100 abstracts reviewed (50 from PubMed; 50 from Google Scholar) none stated unequivocal and conclusive concordance between animals and humans. A low proportion of abstracts $(20 \%)$ described limited concordance 
in specific procedures, but this was generally qualified with an advisory to interpret the findings with caution and the need for more clinical studies to provide better evidence in humans.

Species used in studies included rats, mice, rabbits, cats, dogs, sheep, pigs, and non-human primates, among others. A wide range of disease areas were covered, including several types of cancer, heart disease, stroke, neurological disorders (e.g., Alzheimer's and Parkinson's disease), diabetes, bone defects and facial disorders, dental research, gene therapy and stem cell research, to provide some examples. Several publications were general reviews of how animal data translates to humans, as well as reviews of animal studies in specific disease areas.

The large majority of reviews $(75 \%)$ found that assessment of human response from animal data is significantly limited due to one or more of the following factors: species differences, lack of clinical translation, poor quality methodology, inconsistency, and publication bias, resulting in overstatement of the benefits of animal use in predicting human disease outcomes or safety. There was a distinct lack of evidence clinically, despite many therapies in use based on animal studies. Numerous reviews highlighted the successes claimed over basic research outcomes or new therapies in animal "models", which have, however, failed to translate to the clinic to help patients (Hirst et al., 2016). Concerns over paucity of evidence, publication bias and consequently, overstatement of benefit in translating animal data to humans have led to many systematic reviews (Briel et al., 2013).

A key finding from this review is that, not only is publication bias very common in animal research, but many additional results considered unsuccessful remain unpublished. This issue was raised in a number of the systematic reviews analyzed, for example in animal models of stroke (Sena et al., 2010). Several reviews also raised concerns over animal studies and human trials being carried out simultaneously (Horn et al., 2001; Lucas et al., 2002). Moreover, this analysis found several studies ( $5 \%$ of the sample reviewed), highlighting animal experiments that could have been entirely omitted and carried out directly and far more effectively and ethically in clinical or observational studies in humans; for example, studies on dietary intake and cardiovascular health (Reis et al., 2016; Raynor et al., 2015), or trials of substances already in human use (Rogers et al., 2016). In many cases, human trials were carried out in parallel with animal experiments, representing examples of animal use that can be abandoned. This is discussed later in this chapter in more detail.

The findings from the majority of publications reviewed are consistent with other evidence on the problems of translating animal data to humans; for example, the Review of Research Using Non-human Primates (jointly 
commissioned in 2006 by a number of major $\mathrm{UK}$ research councils and chaired by Sir David Weatherall). A subsequent review in 2011 addressed one of the recommendations in the Weatherall report, to review ten years of brain research in monkeys retrospectively. Not only did the review reveal some disturbing insights into the routine suffering of non-human primates used in neurology, but it reported the equally concerning finding that "In most cases, however, little direct evidence was available of actual medical benefit in the form of changes in clinical practice or new treatments" (Biotechnology and Biological Sciences Research Council, 2011, p. 13). These findings were emphasized more recently in the Review of the Assessment of Cumulative Severity and Lifetime Experience in Non-human Primates Used in Neuroscience Research, published in November 2013 by the (then) Animal Procedures Committee (APC, now Animals in Science Committee) (APC, 2013).

Further evidence of increasing concern over the validity of animal research was highlighted in a British Medical Journal review entitled, How Predictive and Productive is Animal Research?, which concluded that "Funds might be better directed towards clinical rather than basic research, where there is a clearer return on investment in terms of effects on patient care" (Godlee, 2014, p. 1). This article adds to a wealth of evidence on the poor performance of animals in predicting human responses, with an accuracy of approximately 20\%-60\%, depending on reviews cited (Perel et al., 2007; van Meer et al., 2012). Additionally, in a series of studies between 2013-2015, a collaboration between the Fund for the Replacement of Animals in Medical Experiments and Cruelty Free International involved the analysis of an unprecedented level of independent data from both preclinical toxicity studies and human clinical trials. The studies revealed the inadequacies of animal toxicity studies in a number of species (i.e., dog, rabbit, mouse, rat, and non-human primate) in predicting human adverse events; and the urgency for more human-relevant methods to be developed (Bailey et al., 2013, 2014, 2015).

To some extent the pharmaceutical industry recognizes that the models it has been using are inadequate. There is encouraging research into alternative approaches and further consideration of the problem in some areas (Bloomberg, 2013). In 2014, the National Institutes of Health (NIH), Tissue Chip Program, began the investigation of more than 100 drugs that showed success in rodents but went on to fail in human trials ( $\mathrm{NIH}, 2016)$.

With regard to the purpose of experiments covered by the reviews examined, the majority of publications focused on basic research in animals (66\%). This was expected, given that this is the largest area of animal use. The remaining $34 \%$ were concerned with reviewing safety or efficacy of substances, including new and existing drugs, herbal therapies, or food related additives or substances (e.g., low calorie sweeteners) (Rogers et al., 2016). 


\section{Review of Toxicity Studies in Animals, Focusing on Three Well- known Examples}

A follow-up literature review was performed to further address publications of toxicity tests in animals. This specific sample of the most recent literature was chosen to provide meaningful case studies on three well-known and widelyused drugs worldwide: paracetamol (acetaminophen), aspirin and penicillin. Information on these studies is presented in Table 15.2, and each drug is briefly discussed below.

\subsection{Paracetamol}

Paracetamol was first marketed in the 1950's (Sneader, 2005) and is well known as one of the world's most common household drugs, traded under many different brand names, including Tylenol and Panadol. Despite being marketed for over five decades and the vast availability of data on global human use, paracetamol continues to be routinely tested on animals, both for "blue sky" research and attempts to market it for new purposes. Using a similar methodology to the previous review, the general key search terms of "paracetamol toxicity animals" resulted in 2,431 listings in PubMed. (Note: Using similar terms "acetaminophen toxicity animals" provided 2,358 listings and a brief review established, as expected, that many of these were the same results).

Review of the first five listings under the above search term, published between 2014-2016, provided extensive evidence of ongoing experimental research into paracetamol in animals. For example, hepatotoxicity has been well known for decades as a risk of paracetamol overdose in humans, yet, inducing such effects in mice is still carried out routinely, worldwide (Pingili et al., 2015). Further recent studies show that macaques are considered a poor model due to their resistance to paracetamol poisoning when compared to humans (Yu et al., 2015). Experimental dosing and killing of newborn mice continues (Viberg et al., 2014), despite paracetamol's widespread global use in children and pregnant mothers, as shown by far more directly relevant clinical or observational studies to check for effects on offspring (Liew et al., 2014). Other experimental studies included, force feeding of GM mice with a drug to inhibit an enzyme that activates the toxic response to paracetamol in order to investigate resistance (Pu et al., 2016), and numerous similar, experimental testing in mice (Hohmann et al., 2013), despite much earlier, advanced human-based studies to investigate resistance to paracetamol toxicity (McCloskey et al., 1999).

Another publication investigated a widely-used industrial chemical that humans are routinely exposed to in the environment via air, diet, and water: aniline. The aim of the study was to investigate aniline's conversion to paracetamol, and its effects on male fertility. Yet, instead of employing the 
TABLE 15.2 Review of publications relating to paracetamol, aspirin, and penicillin

101 Atli, O., Demir-Ozkay, U., Ilgin, S., Aydin, T., Akbulut, E. and PubMed Sener, E. (2016). Evidence for Neurotoxicity Associated with Amoxicillin in Juvenile Rats. Human \& Experimental Toxicology, 35(8), pp. 866-876.

102 Cappon, G., Gupta, U., Cook, J., Tassinari, M. and Hurtt, M. PubMed (2003). Comparison of the Developmental Toxicity of Aspirin in Rabbits When Administered Throughout Organogenesis or During Sensitive Windows of Development. Birth Defects Research Part B: Developmental and Reproductive Toxicology, 68(1), pp. 38-46.

103 Chao, Y., Lee, C., Liu, K., Wang, Y., Wang, C. And Liu, S.(2015).

PubMed Sustained Release of Bactericidal Concentrations of Penicillin in the Pleural Space via an Antibiotic-eluting Pigtail Catheter Coated with Electrospun Nanofibers: Results from In Vivo and In Vitro Studies. International Journal of Nanomedicine, 4(10), pp. 3329-3336.

104 Feinstein, A., Heinemann, L., Curhan, G., Delzell, E., PubMed DeSchepper, P., Fox, J., Graf, H., Luft, F., Michielsen, P., Mihatsch, M., Suissa, S., van der Woude, F. and Willichet, S. (2000). Relationship Between Nonphenacetin Combined Analgesics and Nephropathy: A Review. Kidney International, 58(6), pp. 2259-2264.

105 Holm, J., Chalmey, C., Modick, H., Jensen, L., Dierkes, G., Weiss,

PubMed T., Jensen, B., Nørregard, M., Borkowski, K., Styrishave, B., Koch, H., Severine, M., Jegou, B., Kristiansen, K. and Kristensen, D. (2015). Aniline Is Rapidly Converted into paracetamol impairing Male Reproductive Development. Toxicological Sciences, 148(1), pp. 288-298.

106 Hueper, K., Elalfy, M., Laenger, F., Halter, R., Rodt, T., Galanski, PubMed M. and Borlak, J. (2012). PET/CT Imaging of c-Myc Transgenic Mice Identifies the Genotoxic N-nitroso-diethylamine as Carcinogen in a Short-term Cancer Bioassay. PLoS One, 7(2), p. e30432.

107 Huggett, A., Schilter, B., Roberfroid, M., Antignac, E. and PubMed Koeman J.H. (1996). Comparative Methods of Toxicity Testing: Consensus Document Following an International Life Sciences Institute-ILSI Europe Workshop Held in May 1995. Food and Chemical Toxicology, 34(2), pp. 183-192. 

Critical Illness: A Review. Critical Care and Resuscitation, 14(1), pp. 74-8o.

109 Jegatheeswaran, S. and Siriwardena, A. (2010). Experimental and Clinical Evidence for Modification of Hepatic Ischaemiareperfusion Injury by $\mathrm{N}$-acetylcysteine During Major Liver Surgery. The Official Journal of the International Hepato Pancreato Biliary Association, 13, pp. 71-78.

110 Li, J., Yu, Y., Yang, Y., Liu, X., Zhang, J., Li, B., Zhou, X., Niu, J., Wei, PubMed X. and Liu, Z. (2012). A 15-day Oral Dose Toxicity Study of Aspirin Eugenol Ester in Wistar Rats. Food and Chemical Toxicology, 5o(6), pp. 1980-1985.

111 López-Ruiz, E., Vega-Flores, G., Contreras-Cisneros, B., PubMed Martínez, A. and Rivera-García, A. (2015). Effect of Partial and Generalised Epileptic Seizures on Sleep Architecture in Rats. Revista De Neurologia, 1,6o(7),pp. 289-295.

112 McGill, M. and Jaeschke, H. (2014). Mechanistic Biomarkers in PubMed Acetaminophen-induced Hepatotoxicity and Acute Liver Failure; From Preclinical Models to Patients Expert Opinion on Drug Metabolism \& Toxicology, 10(7), pp. 1005-1017.

113 Pingili, R., Pawak, A. and Challa, S. (2015). Systemic Exposure PubMed of Paracetamol (Acetaminophen) Was Enhanced by Quercetin and Chrysin Co-administration in Wistar Rats and In Vitro Model: Risk of Liver Toxicity. Drug Development and Industrial Pharmacy, 41(11), pp. 1793-180o.

114 Pu, S., Ren, L., Liu, Q., Kuang, J., Shen, J., Cheng, S., Zhang, PubMed Y., Jiang, W., Zhang, Z., Jiang, C. and He, J. (2016). Loss of 5-lipoxygenase Activity Protects Mice Against Paracetamolinduced Liver Toxicity. British Journal of Pharmacology, 173(1), pp. $66-76$.

115 Raza, H., John, A. and Shafarin J. (2014). NAC Attenuates LPSPubMed induced Toxicity in Aspirin-Sensitized Mouse Macrophages via Suppression of Oxidative Stress and Mitochondrial Dysfunction. PLoS One, 9(7), p. e103379.

116 Viberg, H., Eriksson P., Gordh, T. and Fredriksson, A. (2014). Paracetamol (Acetaminophen) Administration During Neonatal Brain Development Affects Cognitive Function and Alters Its Analgesic and Anxiolytic Response in Adult Male Mice. Toxicological Sciences, 138(1), pp. 139-147. 
TABLE 15.2 Review of publications relating to paracetamol, aspirin, and penicillin (cont.)

directly relevant approach of investigating the vast amount of already available clinical and observational exposure data, groups of mice were injected, before being killed and dissected along with their offspring, for examination (Holm et al., 2015).

As well as review of specific experiments on paracetamol toxicity in animals, further publications published between 1996 and 2012 on systematic reviews of paracetamol toxicity were analyzed (see Table 15.2). Included were reviews of translating animal models of paracetamol toxicity to humans, stating that "Considerable effort has been made to predict and model druginduced liver injury in humans using laboratory animals with only little success and even some controversy" (McGill and Jaeschke, 2014, p. 10). A further review of paracetamol, and similar drugs in its class, concluded that there was insufficient evidence based on animal (and human) tests to assess toxic effects on the human kidney (Feinstein et al., 2000). An analysis of clinical treatment for paracetamol-induced injury during liver surgery documented 19 different studies carried out on mice, rats, dogs, and pigs with varying results, concluding that evidence was insufficient to suggest the therapy was clinically relevant (Jegatheeswaran and Siriwardena, 2010).

The remaining reviews focused on how paracetamol, over two decades ago (as one of a group of "well-studied" hepatoxicants), highlighted the need to evaluate links between in vitro and in vivo testing strategies (Huggett et al., 1996); and more recently, despite the extensive toxicity testing of paracetamol, evidence supporting its use in specific groups of patients (e.g., the critically ill) was considered lacking (Jefferies et al., 2012), highlighting the value of data that can only be gathered in clinical research. When taken in normal regular doses, paracetamol is largely considered safe in humans for a number of pain associated conditions. Yet, it causes a wide range of toxicities in many species, for example, cancer in mice and rats (Hueper et al., 2012). In fact, given 
requirements today for extensive regulatory toxicity testing in animals, it is highly likely that paracetamol would be denied approval based on its poor safety profile in animals.

\subsection{Acetylsalicylic Acid (Aspirin)}

Acetylsalicylic acid, commonly known as Aspirin, has been in human use for more than a century. It is still considered successful; and given its relatively cheap production costs and widespread use for a number of indications, it is still considered a "blockbuster" drug in terms of revenue (Hartung, 2009). Yet, the human relevant dose of aspirin is lethal to rats and causes toxic effects in many animal species, including embryonic deformities in dogs, cats, mice, rats, monkeys, and rabbits (Barrow, 2002). Like paracetamol, given the poor safety record of aspirin in animals, it would very likely be denied approval for human use if newly marketed, according to today's regulatory testing requirements (Hartung, 2009). Aspirin continues to be routinely tested on animals, despite availability of vast libraries of both historical and new human data.

With the same methodology and sampling as the previous reviews, the search terms, "aspirin toxicity animals" were used. PubMed revealed experiments carried out between 2012-2016, including 15-day oral toxicity studies of derivatives of aspirin in Wistar rats and subchronic toxicity studies in mice (see Table 15.2). Searching for publications under the terms "acetylsalicylic acid toxicity in animals" resulted in specific studies published between 2000-2013. These included administration of large doses to pregnant rabbits, concluding that aspirin is not teratogenic to them, and highlighting inconsistencies with previous rabbit experiments and species differences with rats, having been "extensively studied" and exhibiting birth defects (Cappon et al., 2003).

\subsection{Penicillin}

Alexander Fleming's pioneering work on penicillin is well known. Following this, Florey and Chain won a Nobel Prize in the 1940's for successful results in mice with penicillin; yet, they considered themselves fortunate to have chosen to test mice instead of guinea pigs, who showed lethal side effects to the drug, as Florey later remarked: "Mice were used in the initial toxicity tests because of their small size, but what a lucky chance it was, for in this respect man is like the mouse and not the guinea pig. If we had used guinea pigs extensively we should have said that penicillin was toxic and we probably should not have proceeded to try and overcome the difficulties of producing the substance for trial in man" (Florey, 1953, p. 12).

In fact, penicillin is safe, to some extent, in mice and rats but has severe, often lethal, effects in hamsters and guinea pigs due to their very sensitive 
intestinal microbiota, making them particularly susceptible when compared to other species. Animal users are quick to respond to this issue, stating that multiple species are used to assess the most appropriate "model" for humans and account for differences (heterogeneity) in animals. Again, no dispute is made on this; indeed, this has been the tenet in toxicology for decades, testing in different species and varying doses, modifying their condition either genetically, chemically or physically in an attempt to elicit the reaction needed. Yet, the high attrition rate of new pharmaceuticals and lack of progress in key areas of disease research should suggest that something is wrong. The use of animals is the only area of scientific research where the same dated techniques are still being used 60-70 years later, despite their limitations being well known. No other area of science continues to use such a dogmatic approach. As evidence of this, a general literature review of the search terms "penicillin toxicity animals" results in numerous publications over decades, several of the most recent listings (2011-2016, see Table 15.2) involving rats, rabbits, and other animals; even using penicillin in repeated experiments to induce effects, including anxiety and depression (to try to mimic effects in rats already seen in patients), weight loss, organ failure, and deliberate epilepsy to test the effects of other drugs that, like penicillin, are already in extensive global use, with a wealth of clinical toxicity data available.

\section{3}

\section{Part 2: Drivers for Change—Development of Animal-free Testing Methods}

It should be noted that use of the term alternatives in this chapter refers only to methods that replace the use of animals and their tissues. It is necessary to make this distinction, given the widely-used terminology of the $3 \mathrm{Rs}$ (replacement, reduction and refinement), first proposed in The Principles of Humane Experimental Technique (Russell and Burch, 1959). The ultimate goal of Russell and Burch in establishing the 3 Rs was replacement. While measures to refine methods or reduce animal numbers are, of course, to be encouraged, much attention is devoted to these $2 \mathrm{Rs}$ and, to some extent, it has diverted focus from replacement.

Given six decades of the ${ }_{3} \mathrm{R}$ principles, dedicated attention to replacement is long overdue. This is also reflected in European Directive 2010/63/EU on animals used for scientific purposes (European Parliament, 2010, p. 2), which states that it "represents an important step towards achieving the final goal of full replacement of procedures on live animals for scientific and educational purposes as soon as it is scientifically possible to do so. To that end, it seeks to 
facilitate and promote the advancement of alternative approaches." Although the Directive was implemented in January 2013, there has been relatively little decrease and, in many cases, an increase in animal use across individual Member States. Therefore, there is still great scope for improvement, particularly with regard to funding the development, acceptance, and adoption of animalfree, human-based methods.

Furthermore, the broad interpretation of the term alternatives under the auspices of the ${ }_{3} \mathrm{Rs}$ is used to describe the use of some animals as "alternatives" to others, for example the use of zebrafish over rodents (Charles River, 2016); transgenic mice to "replace" non-human primates (Home Office, 2014); and even the use of minipigs, instead of dogs, as an "alternative" that may be more acceptable to the public, because they are considered "food animals" (Forster et al., 2010). Aside from the poor ethical argument, replacing one animal with another still fails to address the wrong model problem.

Use of public opinion and political lobbying to drive legislative change remains vital to fueling research and developments in animal-free science. The clearest example in recent years is the phased-in bans on animal-tested cosmetics across the EU between 2009-2013 (European Commission, 2013). A testing ban on cosmetic ingredients was enforced from March 11, 2009, along with a partial marketing ban for 10 animal-test requirements. This was eventually followed by a further marketing ban from March 11, 2013 for endpoints considered more complex (i.e., repeat dose toxicity, skin sensitization, reproductive toxicity, carcinogenicity, and toxicokinetics). However, for safety data requirements of cosmetic substances, some of these endpoints are rarely or not required (Nohynek et al., 2010). Despite delays in implementing the bans and legal challenges attempting to abolish them altogether, they had a monumental effect on the industry, with the development of numerous in vitro methods to be ready in time. Despite loopholes with conflicting chemicals safety-testing legislation, such as Registration, Evaluation, Authorisation and Restriction of CHemicals (REACH) (European Chemicals Agency, 2007), the bans have been responsible for one of the most significant advances towards replacing animal tests in decades.

The campaign to end cosmetics tests on animals began in the 1970s, and it took until 1993 to see legislation amendments to mark the implementation of official Eu bans. After a further two decades of delays, the bans were finally enforced, with significant resistance amid claims that innovation would be stifled and that the development of alternatives would not be possible. Instead, the opposite was achieved. The development of in vitro methods was stimulated to address a number of toxicological endpoints (the result of a study to determine how toxic a substance is). The endpoints included skin irritation, eye irritation, 
skin corrosion, phototoxicity, skin absorption/penetration, acute toxicity, and genotoxicity/mutagenicity. In preparation for the forthcoming bans, around 30 new in vitro assays were validated by 2007 (Hartung, 2008), with more developed since and projections that the in vitro toxicity testing market will be worth US $\$ 17,227$ million by 2018 (PR Newswire, 2014). The bans have also affected positive change outside $\mathrm{EU}$ borders, with similar bans now in place in India, Israel, Norway, and New Zealand, as well as partial or full enforcements in many other countries.

Methods Now Available, Previously Considered Only Possible in Animals-Some Examples

Replacement can be (and is being) achieved by a number of approaches, including in vitro and in silico models. Some examples are discussed below.

In its 2014 Delivery Plan, Working to reduce the use of animals in scientific research, the UK Home Office devoted much of the text to supporting the continuance of animal research. However, the plan also showcases human in vitro methods, for example, using induced pluripotent stem cells (Yusa et al., 2011), which it describes as "work that in the past could only have been modelled in animal systems" (Home Office, 2014, p. 16).

Scientists at the University of Newcastle have developed human skin-based assays, using cells isolated from the blood sample of healthy volunteers to assess new drugs, cosmetics and household products. The technology, now marketed as Skimune by Alcyomics Ltd, could have predicted the adverse effects seen in the volunteers of the TGN1412 monoclonal antibody clinical trial in 2006 (Alcyomics, 2017).

Other high performance initiatives include physiologically-based pharmacokinetic modelling ( $\mathrm{PBPK}$ ), which quantitatively predicts the characteristics of substances in the body (e.g., blood flow or effects on organs). The introduction of in vitro PBPK models over the past two decades is credited with reducing drug failure rates from over $40 \%$ to under $10 \%$ (McKim, 2010). Another major area of replacement research uses devices, known as Multi Organ Chips (MOC), to mimic the human body's response to chemicals and disease processes, with the ultimate goal being a human on a chip. Over the past few years, advances in MOc technology have been exponential. For example, the organ on a chip devices developed at Harvard's Wyss Institute can mimic events in tissue function and disease, such as air flow, bacterial infection, immune system response, blood clotting, fluid leakage and, most recently, electrical activity across cells, to predict safety and disease mechanisms in patients (Wyss Institute, 2017). For further discussion see Wilkinson, 2019, Chapter 26. 
At the United States NIH Chemical Genomics Centre, a major testing program has been underway since 2004, involving a robotic-arm system that tests thousands of chemicals, using patient donated cells. The high throughput system performs approximately 3 million tests per week in relation to a different disease. The success of the system (also funded under the Toxicology in the 21st Century, Tox21, initiative) in screening and identifying suitable candidate drugs has dramatically saved time, cost, and resources, resulting in human clinical trials starting within a year.

A further groundbreaking concept is the Adverse Outcome Pathway (AOP), a key component of the paradigm shift towards human-relevant methods and establishing a robust system for predicting human safety. An AOP is a sequence of events that starts by a chemical effect at the molecular level (termed a Molecular Initiating Event) and progresses through changes (termed Key Events) in cells, tissues, and organs to produce an adverse effect in the body. AOPs act as a bridge between emerging methods of safety testing and, ultimately, what happens in the body in response to a particular substance (xenobiotic). With increasing knowledge, AOPs can be linked to form networks, revealing adverse outcomes that share pathways and vice versa. One example is the establishment of in vitro test methods that map the three key stages of the AOP for skin sensitization, now accepted at Organisation for Economic Co-Operation and Development (OECD) level (2015). Before the EU cosmetic testing bans were implemented, there was a high level of skepticism over the prospect of testing substances for skin sensitization (and other complex endpoints) without the use of animals; and while further work remains to be done, major progress has been made. The AOP program was established in 2012 and, including skin sensitization, there are now six AOPs approved at the OECD level; five relating to human health effects and one to address potential ecotoxicological effects to wildlife (fish, birds, and amphibians). A further 227 AOPS are in development (OECD, 2017).

In addition to new in vitro and in silico models to address safety testing, other areas of animal use previously considered essential, such as education, have seen coordinated replacement initiatives. Although animals are still used extensively in this area, great successes have been achieved to date. For example, campaigns by all involved in the International Network for Humane Education (InterNICHE) project to provide training and disseminate information on humane methods in medicine, biology, and veterinary research (e.g., mannequins and simulation techniques) continue to affect great change in universities and schools worldwide (InterNICHE, 2017). Other progress is being made in education as well. In 2016, Washington University announced it would end its 25year use of cats for intubation training (the last university in the United States still using cats in this way). Instead, it will now use mannequins and advanced 
simulators, following significant investment in its simulation center, which made the decision possible, following sustained public awareness campaigns (Physicians Committee for Responsible Medicine, 2016). Also in 2016, Johnson and Johnson subsidiary, Ethicon, finally agreed to remove live pigs from its medical-device training program, stating that it "discontinued live animal use in salestrainingacrossourNorthAmericaregion"(PeoplefortheEthicalTreatmentof Animals, 2016). For further discussion see Pawlowski, et al., 2019, Chapter 22.

In addition to the vast range of human-based technologies now available, another sensible approach is to improve the use of data from clinical, epidemiological, and biomonitoring studies. All of these have been considerably underused to date and could not only improve patient-safety and disease research but avoid the unnecessary use of animals.

\section{$5 \quad$ Abandonment of Redundant and Duplicative Animal Tests}

The ethical arguments concerning use of animals and problems with scientific validity are compounded further by the issue of duplicative experiments, which is a widespread problem. Many of the same tests are carried out over and over again, often amid claims of needing to maintain confidentiality and preserving intellectual property, despite mandates to share data. One example, a robust analysis of safety data submitted under the REACH program, recently revealed that, incredibly, the Draize eye irritation test had been carried out on rabbits for two chemicals, go times per substance. (Luechtefeld et al., 2016).

Not all tests need replacing. Many can end now as they are out of date or have been found to be redundant. A recent case is the deletion of the singledose toxicity test from the European Medicines Agency guidelines, after it was recognized that information from the test could be obtained elsewhere, and that the test was of limited value (European Medicines Agency, 2010). Furthermore, there are many examples of animal tests that require a root and branch analysis and retrospective assessment to not only assess whether scientific objectives were met but also whether such procedures should have been approved at all. A case study to demonstrate this further is the European Coalition to End Animal Experiments (ECEAE). In 2014, ECEAE estimated that its strategy of toxicological review and comment on animal testing proposals for chemicals registered under the REACH legislation saved at least 18,00o animals, through rejected and withdrawn proposals. This was achieved on the basis of existing data or evidence that the tests proposed were unnecessary or unjustified (ECEAE, 2014). Another recent example is the welcome decision that the year-long chronic-toxicity test for pesticides is no longer required in dogs, on the basis that it is not scientifically justified (Kobel et al., 2010). The test has 
been dropped in the EU, the United States, and Canada. Although there are still requirements for the one-year test to be carried out in other countries, the restrictions mark a change in attitudes and a meaningful review of testing requirements. The campaign continues to see the test abolished worldwide as soon as possible.

\section{Conclusion}

The aim of this chapter was to provide a qualitative overview of evidence from systematic reviews and some individual studies of not only the flawed approach to the continued use of animals in trying to predict mechanisms of human disease; but also the success of existing and emerging animal-free methods, the opportunities for intelligent use of human-based data, and the distinction between animal tests that require replacement and those that can simply end.

Advances in science, providing better technologies on an ongoing basis, should pave the way for acceptance of non-animal methods. In some areas, such as cosmetics testing, there is unprecedented change and global recognition that animal use must end. Yet, in other areas of animal research, despite a wealth of better science, the realities of some conventional attitudes, resistance to change, and an industry reliant on the continuation of animal experimentation (e.g., major establishments funded by long-term programs of animal research, financial partnerships, GM animal breeding, commercial breeders, suppliers, and transporters of animals) mean that political lobbying, campaigning, and raising public awareness must continue to play a major role. Fortunately, there are a number of animal protection, political, and scientific stakeholders who continue to work in the field, actively pushing for change, to increase recognition that animal research must end and to achieve the paradigm shift that is urgently needed for humans and animals.

\section{Dedication}

This chapter is dedicated to Andrew Tyler.

\section{References}

Alcyomics Ltd. (2017). Case Study 1. Northwick Park. [online] Available at: http:// alcyomics.com/case-studies/northwick-park/ [Accessed 16 February 2017]. 
Animal Procedures Committee (APC) (2013). Review of the Assessment of Cumulative Severity and Lifetime Experience in Non-human Primates Used in Neuroscience Research. London:. [online] Available at: https:/www.gov.uk/government/uploads/ system/uploads/attachment_data/file/261687/cs_nhp_review_FINAL_2013 _corrected.pdf [Accessed 30 November 2016].

Bailey, J., M. Thew and M. Balls (2013). An Analysis of the Use of Dogs in Predicting Human Toxicology and Drug Safety. Alternatives to Laboratory Animals, 41, pp. 335-350.

Bailey, J., M. Thew and M. Balls (2014). An Analysis of the Use of Animal Models in Predicting Human Toxicology and Drug Safety. Alternatives to Laboratory Animals, 42, pp. 181-199.

Bailey, J., M. Thew and M. Balls (2015). Predicting Human Drug Toxicity and Safety via Animal Tests: Can Any One Species Predict Drug Toxicity in Any Other, and Do Monkeys Help?. Alternatives to Laboratory Animals, 43, pp. 393-403.

Barrow, P. (2002). Preclinical Testing for Teratogenicity and Developmental Toxicity: Methods and Limitations. Therapie, 57(2), pp. 109-114.

Biotechnology and Biological Sciences Research Council (BBSRC) (2011). Review of Research Using Non-human Primates. Report of a panel chaired by Professor Sir Patrick Bateson, FRS. London. [online] Available at: http://www.bbsrc.ac.uk/documents/ review-research-using-nhps-pdf/ [Accessed 30 November 2016].

Bloomberg (2013). Oxford Works with Drug-makers to Reverse 90\% Trial Failure Rate. Bloomberg News. [online] Available at: https://www.bloomberg.com/news/ articles/2013-05-03/billionaire-li-ka-shing-funds-medical-data-institute-at-oxford [Accessed 16 December 2016].

Briel, M., K.F. Müller, J.J. Meerpohl, E. von Elm, B. Lang, E. Motschall, V. Gloy, F. Lamontagne, G. Schwarzer and D. Bassler (2013). Publication Bias in Animal Research: A Systematic Review Protocol. Systematic Reviews, 2(23). [online] Available at: https://www.ncbi.nlm.nih.gov/pmc/articles/PMC $3651300 /$ [Accessed 30 November 2016].

Charles River Laboratories (2016). Zebrafish: A Powerful Alternative Model for Developmental Toxicity Testing. Charles River Technical Sheet. [online] Available at: http:// www.criver.com/files/pdfs/pcs/tox/zebrafish-developmental-toxicity-testingtechnical.aspx [Accessed 11 December 2016].

European Chemicals Agency (2007). Registration, Evaluation, Authorisation and Restriction of CHemicals (REACH). Helsinki. [online] Available at: https://echa.europa.eu/ regulations/reach/ [Accessed 30 November 2016].

European Coalition to End Animal Experiments (ECEAE) (2014). ECEAE Claims 18,ooo Animals Saved Through REACH Testing Proposals Process. London. [online]. Available at: http://www.eceae.org/en/category/latest-news/371/eceaeclaims-1800o-animals-saved-through-reach-testing-proposals-process [Accessed 3 August 2017]. 
European Commission (2013a). Ban on Animal Testing. Brussels. [online] Available at: http://ec.europa.eu/growth/sectors/cosmetics/animal-testing_en [Accessed 30 November 2016].

European Commission (2013b). Seventh Report on the Statistics on the Number of Animals used for Experimental and other Scientific Purposes in the Member States of the European Union. Brussels: SWD (2013), 497 final. [online] Available at: http://eurlex.europa.eu/legal-content/EN/TXT/PDF/?uri=CELEX:52013DCo859\&from=EN [Accessed 30 November 2016].

European Medicines Agency (2010). Questions and Answers on the Withdrawal of the "Note for Guidance on Single Dose Toxicity". [online] Available at: http://www .ema.europa.eu/docs/en_GB/document_library/Scientific_guideline/2010/o7/ WC500094590.pdf [Accessed 3o November 2016].

European Parliament (2010). Directive 2010/63/EU of the European Parliament and of the Council of 22 September 2010 on the protection of animals used for scientific purposes. Official Journal of the European Communities, L276, pp. 33-79. [online] Available at: http://eur-lex.europa.eu/legal-content/EN/TXT/?uri=CELEX\%3 A32010Loo63 [Accessed 12 August 2017].

Federal Ministry of Food and Agriculture (2016). Animal Research Statistics 2015. Berlin. [online] Available at:http://www.bmel.de/SharedDocs/Downloads/Tier/Tierschutz /Versuchstierdaten2015.pdf?_blob=publicationFile [Accessed 25 May 2017].

Florey, H. (1953). The Advance of Chemotherapy by Animal Experiment. Conquest, 41, p. 12.

Forster, R., G. Bode, L. Ellegaard, J.W. van der Laan, and Steering Group of the RETHINK Project. (2010). The RETHINK Project: Minipigs as Models for the Toxicity Testing of New Medicines and Chemicals: An Impact Assessment. Journal of Pharmacological and Toxicological Methods, 62, pp. 158-159.

Godlee, F. (2014) How Predictive and Productive is Animal Research? British Medical Journal, 348, p. 3719.

Google Scholar (2016). [online] Available at: https://scholar.google.co.uk [Accessed 30 November 2016].

Hartung, T. (2008). Food for thought ... on Alternative Methods for Cosmetics Safety Testing. Alternatives to Animal Experimentation, p. 25.

Hartung, T. (2009). Per Aspirin Ad Astra. Alternatives to Laboratory Animals, 37(2), pp. $45^{-47}$.

Hirst, T.C., R. Watzlawick, J.K. Rhodes, M.R. Macleod and P.J. Andrews (2016). Study Protocol: A Systematic Review and Meta-analysis of Hypothermia in Experimental Traumatic Brain Injury: Why Have Promising Animal Studies Not Been Replicated in Pragmatic Clinical Trials? Evidence-based Preclinical Medicine, 3(2), p. eooozo.

Hohmann, S., R.Cardoso, F.Pinho-Ribeiro,J.Crespigio, T.Cunha,J.Alves-Filho, R. daSilva, P.Pinge-Filho, S. Ferreira, F. Cunha, R. Casagrande and W.Verri (2013) 5 -lipoxygenase 
deficiency reduces acetaminophen-induced hepatotoxicity and lethality. BioMed Research International, 627046.

Holm, J., C. Chalmey, H. Modick, L. Jensen, G. Dierkes, T. Weiss, B. Jensen, M. Nørregard, K. Borkowski, B. Styrishave, H. Koch, M. Severine, B. Jegou, K. Kristiansen and D. Kristensen (2015). Aniline Is Rapidly Converted into Paracetamol Impairing Male Reproductive Development. Toxicological Sciences, 148(1), pp. 288-298.

Home Office (2014). Working to Reduce the Use of Animals in Scientific Research: Delivery Plan. London. [online] Available at https://www.gov.uk/government/public ations/working-to-reduce-the-use-of-animals-in-research-delivery-plan [Accessed 30 November 2016].

Home Office (2017). Statistics of Scientific Procedures on Living Animals, Great Britain 2016. London. [online] Available at: https:/www.gov.uk/government/uploads/ system/uploads/attachment_data/file/627284/annual-statistics-scientificprocedures-living-animals-2016.pdf [Accessed 30 November 2016].

Horn, J., R. de Haan, M. Vermeulen, P. Luiten and M. Limburg (2001). Nimodipine in Animal Model Experiments of Focal Cerebral Ischemia: A Systematic Review. Stroke, 32(10), pp. 2433-2438.

International Network for Humane Education (InterNICHE) (2017). [online]. Available at: http://www.interniche.org [Accessed 6 August 2017].

Kobel, W., I. Fegert, R. Billington, R. Lewis, K. Bentley, W. Bomann, P. Botham, B. Stahl, B. Ravenzwaay and H. Spielmann (2010). A 1-year Toxicity Study in Dogs Is No Longer a Scientifically Justifiable Core Data Requirement for the Safety Assessment of Pesticides. Critical Reviews in Toxicology, 40(1), pp. 1-15.

Lawrence, J. (2014). An Out of Body Experience. The Pharmaceutical Journal. [online] Available at: http://www.pharmaceutical-journal.com/news-and-analysis/feature/ organ-on-chip-technology-to-revolutionise-drug-development/20065894.article [Accessed 30 November 2016].

Liew, Z., B. Ritz, J. Virk and J. Olsen (2014). Maternal Use of Acetaminophen During Pregnancy and Risk of Autism Spectrum Disorders in Childhood: A Danish National Birth Cohort Study. Autism Research, 9(9), pp. 951-958.

Lucas, C., L. Criens-Poublon, C. Cockrell and R.J. de Haan (2002). Wound Healing in Cell Studies and Animal Model Experiments by Low Level Laser Therapy. Were Clinical Studies Justified? A Systematic Review. Lasers in Medical Science, 17(2), pp. 110-134. Luechtefeld, T., A. Maertens, D. Russo, C. Rovida, H. Zhu and T. Hartung (2016) Analysis of Draize E Eye Irritation Testing and Its Prediction by Mining Publicly Available 2008-2014 REACH Data. Alternatives to Animal Experimentation, 33(2), pp. 123-134.

McCloskey, P., R. Edwards, R. Tootle, C. Selden, E. Roberts and H. Hodgson (1999). Resistance of Three Immortalized Human Hepatocyte Cell Lines to Acetaminophen and $\mathrm{N}$-acetyl-p-benzoquinoneimine Toxicity. Journal of Hepatology, 31(5), pp. 841-851. 
McKim, J. Jr. (2010). Building a Tiered Approach to In Vitro Predictive Toxicity Screening: A Focus on Assays with In Vivo Relevance. Combinatorial Chemistry \& High Throughput Screening, 13(2), pp. 188-206.

Ministry of Higher Education and Research (2016). Use of Animals for Scientific Purposes in French User Establishments: Statistical Survey 2014. Paris. [online] Available at: http://cache.media.enseignementsup-recherche.gouv.fr/file/utilisation_des _animaux_fins_scientifiques/84/2/Enquete_2014_-_utilisation_des_animaux_a_des _fins_scientifiques_591842.pdf [Accessed 30 November 2016].

National Center for Advancing Translational Sciences (NCATS) (2017). Transforming Translational Science. [online] Available at: https://ncats.nih.gov/files/NCATSfactsheet.pdf [Accessed 7 February 2017].

National Centre for Biotechnology Information (2016). PubMed. [online] Available at: https://www.ncbi.nlm.nih.gov/pubmed/ [Accessed 3o November 2016].

National Institutes of Health (NIH) (2016). About Tissue Chip. [online] Available at: https://ncats.nih.gov/tissuechip/about [Accessed 30 November 2016].

Netherlands National Committee for the protection of animals used for scientific purposes (NCad) (2016). Opinion Transition to Non-animal Research. The Hague. [online] Available at: https://english.ncadierproevenbeleid.nl/latest/news/16/12/15/ ncad-opinion-transition-to-non-animal-research [Accessed 30 November 2016].

Nohynek, G., E. Antignac, T. Re and H. Toutain (2010). Safety Assessment of Personal Care Products/Cosmetics and Their Ingredients. Toxicology and Applied Pharmacology, 243; pp. 239-259.

OECD (2017) Adverse Outcome Pathway (AOP) Knowledge Base. [online] Available at: http://aopkb.org/ [Accessed 6 August 2017].

Organisation for Economic Co-Operation and Development (OECD) (2015). The Adverse Outcome Pathway for Skin Sensitisation Initiated by Covalent Binding to Proteins. [online] Available at: http://www.oecd.org/env/the-adverse-outcome-pathway-forskin-sensitisation-initiated-by-covalent-binding-to-proteins-9789264221444-en. htm [Accessed 30 November 2016].

People for the Ethical Treatment of Animals (PETA) (2016). Letter from Johnson and Johnson Animal Care and Use Council to PETA Laboratory Investigations Division. [online] Available at: http://freepdfhosting.com/be28b65dbf.pdf [Accessed 6 August 2017].

Perel, P., I. Roberts, E. Sena, P.Wheble, C. Briscoe, P. Sandercock, M. Macleod, M. Luciano, P. Jayaram and K. Khan (2007). Comparison of Treatment Effects Between Animal Experiments and Clinical Trials: Systematic Review. British Medical Journal, 334(7586), p. 197.

Physicians Committee for Responsible Medicine (2016). Physicians Committee Commends Washington University for Ending Animal Labs. [online]. Available at: https:// 
www.pcrm.org/pcrm.org/media/news/washington-university-ends-live-cat-labsfor-pediatrics-training [Accessed 6 August 2017].

Pingili, R., A. Pawak and S. Challa (2015). Systemic Exposure of Paracetamol (Acetaminophen) Was Enhanced by Quercetin and Chrysin Co-administration in Wistar Rats and In Vitro Model: Risk of Liver Toxicity. Drug Development and Industrial Pharmacy, 41(11), pp. 1793-1800.

PR Newswire (2014). In Vitro Toxicology Testing Market Worth \$17,227 Million by 2018. [online] Available at: http://www.prnewswire.co.uk/news-releases/in-vitro-toxicol ogy-testing-market-worth-17227-million-by-2018-253586361.html [Accessed 10 July 2017].

Ramirez, T., S. Beken, M. Chlebus, G. Ellis, C. Griesinger, S. De Jonghe, I. Manou, A. Mehling, K. Reisinger, L. Rossi, J. van der Laan, R. Weissenhorn and U. Sauer (2015). Knowledge Sharing to Facilitate Regulatory Decision-making in regard to Alternatives to Animal Testing: Report of an EPAA Workshop. Regulatory Toxicology and Pharmacology, 73(1), pp. 210-226.

Raynor, H.A., M.R. Goff, S.A. Poole and G. Chen (2015). Eating frequency, food intake and weight: A systematic review of human and animal experimental studies. Frontiers in Nutrition, $18(2)$, p. 38.

Reis, J., V. Monteiro, R. de Souza Gomes, M. do Carmo, G. da Costa, P. Ribera and M. Monteiro (2016). Action Mechanism and Cardiovascular Effect of Anthocyanins: A Systematic Review of Animal and Human Studies. Journal of Translational Medicine,15-14(1), p. 315 .

Rogers, P.J., P.S. Hogenkamp, C. de Graaf, S. Higgs, A. Lluch, A.R. Ness, C. Penfold, R. Perry, P. Putz, M.R. Yeomans and D. J Mela (2016). Does Low-energy Sweetener Consumption Affect Energy Intake and Body Weight? A Systematic Review, including Meta-analyses of the Evidence from Human and Animal Studies. International Journal of Obesity (London), 40(3), pp. 381-394.

Russell, W. and R. Burch (1959). Principles of humane experimental technique. [online] Available at: http://altweb.jhsph.edu/pubs/books/humane_exp/het-toc [Accessed 30 November 2016].

Schiffelers, M.J., B. Blaauboer, C. Hendriksen and W. Bakker (2012). Regulatory Acceptance and Use of 3 R Models: A Multilevel Perspective. Alternatives to Animal Experimentation, 29(3), pp. 287-300.

Sena, E., H. van der Worp, P. Bath, D. Howells and M. Macleod (2010). Publication Bias in Reports of Animal Stroke Studies Leads to Major Overstatement Of Efficacy. Public Library of Science Biology, 30, 8(3), p. e1000344.

Sneader, W. (2005). Drug discovery. West Sussex, u K: John Wiley \& Sons, Ltd. van Meer, P., M. Kooijman, C. Gispen-de Wied, E. Moors and H. Schellekens (2012) The Ability of Animal Studies To Detect Serious Post Marketing Adverse Events Is Limited. Regulatory Toxicology and Pharmacology, 64(3), pp. 345-349. 
Viberg, H., P. Eriksson, T. Gordh and A. Fredriksson (2014). Paracetamol (Acetaminophen) Administration During Neonatal Brain Development Affects Cognitive Function and Alters Its Analgesic and Anxiolytic Response in Adult Male Mice. Toxicological Sciences, 138(1), pp. 139-147.

Wyss Institute (2017). Wyss Institute's Organ Chips Get Smart And Go Electric. [online] Available at: https://wyss.harvard.edu/wyss-institutes-organ-chips-get-smart-andgo-electric/ [Accessed 6 August 2017].

Yu, H., N. Barrass, S. Gales, E. Lenz, T. Parry, H. Powell, D. Thurman, M. Hutchison, I. Wilson, L. Bi, J. Qiao, Q. Qin and J. Ren (2015). Metabolism by Conjugation Appears to Confer Resistance to Paracetamol (Acetaminophen) Hepatotoxicity in the Cynomolgus Monkey. Xenobiotica, 45(3), pp. 270-277.

Yusa, K. Rashid, S.T., Strick-Marchand, H., Varela, I., Liu P.Q., Paschon D.E., Miranda E., Ordóñez A., Hannan, N.R., Rouhani F.J. and Darche S., (2011). Targeted Gene Correction of a 1-antitrypsin Deficiency in Induced Pluripotent Stem Cells. Nature, 478(7369), pp. 391-394. 